\title{
Relative effectiveness of clinic and home blood pressure monitoring compared with ambulatory blood pressure monitoring in diagnosis of hypertension: systematic review
}

\author{
J Hodgkinson research fellow ${ }^{1}$, J Mant professor ${ }^{2}$, U Martin clinical reader in clinical pharmacology ${ }^{3}$, \\ B Guo research fellow ${ }^{4}$, F D R Hobbs professor ${ }^{1}$, J J Deeks professor ${ }^{4}$, C Heneghan reader in \\ evidence based medicine ${ }^{5}, \mathrm{~N}$ Roberts information specialist ${ }^{6}, \mathrm{R} \mathrm{J}$ McManus professor ${ }^{1}$
}

${ }^{1}$ Primary Care Clinical Sciences, University of Birmingham, Edgbaston, Birmingham B15 2PP; ${ }^{2}$ General Practice and Primary Care Research Unit, University of Cambridge, Cambridge CB2 0SR; ${ }^{3}$ School of Clinical and Experimental Medicine, University of Birmingham, Edgbaston; ${ }^{4} \mathrm{Public}$ Health, Epidemiology and Biostatistics, University of Birmingham, Edgbaston; ${ }^{5}$ Department of Primary Health Care, University of Oxford, Headington, Oxford OX3 7LF; ${ }^{6}$ Bodleian Health Care Libraries, Knowledge Centre, ORC Medical Research Building, Oxford OX3 7DQ

\begin{abstract}
Objective To determine the relative accuracy of clinic measurements and home blood pressure monitoring compared with ambulatory blood pressure monitoring as a reference standard for the diagnosis of hypertension.

Design Systematic review with meta-analysis with hierarchical summary receiver operating characteristic models. Methodological quality was appraised, including evidence of validation of blood pressure measurement equipment.

Data sources Medline (from 1966), Embase (from 1980), Cochrane Database of Systematic Reviews, DARE, Medion, ARIF, and TRIP up to May 2010.

Eligibility criteria for selecting studies Eligible studies examined diagnosis of hypertension in adults of all ages using home and/or clinic blood pressure measurement compared with those made using ambulatory monitoring that clearly defined thresholds to diagnose hypertension.

Results The 20 eligible studies used various thresholds for the diagnosis of hypertension, and only seven studies (clinic) and three studies (home) could be directly compared with ambulatory monitoring. Compared with ambulatory monitoring thresholds of $135 / 85 \mathrm{~mm} \mathrm{Hg}$, clinic measurements over $140 / 90 \mathrm{~mm} \mathrm{Hg}$ had mean sensitivity and specificity of $74.6 \%$ (95\% confidence interval $60.7 \%$ to $84.8 \%$ ) and $74.6 \%$ (47.9\% to $90.4 \%$ ), respectively, whereas home measurements over $135 / 85 \mathrm{~mm} \mathrm{Hg}$ had mean sensitivity and specificity of $85.7 \%(78.0 \%$ to $91.0 \%)$ and $62.4 \%$ (48.0\% to $75.0 \%)$.
\end{abstract}

Conclusions Neither clinic nor home measurement had sufficient sensitivity or specificity to be recommended as a single diagnostic test. If ambulatory monitoring is taken as the reference standard, then treatment decisions based on clinic or home blood pressure alone might result in substantial overdiagnosis. Ambulatory monitoring before the start of lifelong drug treatment might lead to more appropriate targeting of treatment, particularly around the diagnostic threshold.

\section{Introduction}

High blood pressure is a key risk factor for the development of cardiovascular disease ${ }^{1}$ and is a major cause of morbidity and mortality worldwide. ${ }^{2}$ Hypertension is the commonest chronic disorder seen in primary care, with around one in eight of all people receiving antihypertensive treatment. ${ }^{34}$

Initial management of hypertension conventionally requires a diagnosis based on several clinic or office blood pressure measurements..$^{5-7}$ National and international guidelines recommend similar strategies, although the thresholds of blood pressure for diagnosis and risk vary. ${ }^{5-9}$ Ambulatory blood pressure monitoring, however, estimates "true" mean blood pressure more accurately than clinic measurement because multiple readings are taken; it has also been shown to have better correlation with a range of cardiovascular outcomes and end organ damage. ${ }^{10-15}$ Ambulatory blood pressure monitoring is typically used when there is uncertainty in diagnosis, resistance to treatment, irregular or diurnal variation, or concerns about 
variability and the "white coat" effect. ${ }^{16}{ }^{17}$ It has therefore arguably become the reference standard for the diagnosis of hypertension.

Home blood pressure monitoring, which provides multiple readings over several days, is also better correlated with end organ damage than clinic measurement. ${ }^{19}{ }^{20}$ It seems to be a better prognostic indicator with respect to stroke and cardiovascular mortality ${ }^{21-23}$ and can identify white coat and masked hypertension. It could provide an appropriate alternative to ambulatory monitoring in terms of diagnosis, particularly in primary care where it might not be immediately available or deemed too costly or when patients find it inconvenient or uncomfortable. Home monitoring has a smaller evidence base than ambulatory monitoring but has gained acceptance over recent years as data accumulate and accurate equipment becomes more widely available. ${ }^{24} 25$

If guidelines are to retain clinic measurement as a standard diagnostic tool, it is important to assess these in the light of ambulatory measurement. Similarly, for home measurements to be considered as an alternative to ambulatory measurements then their test performance needs to be evaluated. We conducted a systematic review of the test performance of the diagnosis of hypertension by clinic measurement and home monitoring compared with the reference standard of ambulatory monitoring.

\section{Methods}

\section{Inclusion criteria}

We had various criteria for inclusion.

Types of study - Studies had to have extractable data for diagnoses of hypertension made with home and/or clinic blood pressure measurement compared with those made with ambulatory measurement. There was no restriction on language or year of publication.

Types of participants in studies-We included adult patients of all ages. Studies were excluded if participants were pregnant, in hospital, or receiving treatment at the time of the comparison, unless these groups could be excluded from other data within a paper. Although we aimed to derive data relevant to primary care, no restriction was placed on setting other than excluding patients in hospital.

Types of outcome measures-We extracted data into $2 \times 2$ tables for comparisons of the diagnosis of hypertension provided that clearly defined thresholds for the diagnosis of hypertension were used. Studies from which $2 \times 2$ tables could not be derived were excluded.

Reference standard-We chose ambulatory monitoring as the reference standard, with $135 / 85 \mathrm{~mm} \mathrm{Hg}$ as the internationally accepted threshold for diagnosis on mean daytime readings. ${ }^{7}$ Among the various indirect methods of measuring blood pressure, ambulatory monitoring shows the strongest relation with clinical outcome and estimates blood pressure more accurately because multiple readings are taken. ${ }^{10-15}$ It thus represents the most appropriate choice of reference standard. Some studies have suggested that night time average blood pressure is superior to daytime at predicting cardiovascular outcomes, ${ }^{26}$ but there is greater consensus over the threshold to use for daytime averages than night time averages. ${ }^{5} 7$

\section{Search strategy}

We searched Medline (from 1950 onwards), Embase (from 1980 onwards), the Cochrane Database of Systematic Reviews, DARE, Medion (www.mediondatabase.nl), ARIF (www.arif. bham.ac.uk), and the TRIP database (www.tripdatabase.com) up to May 2010, using a search strategy designed to capture all studies evaluating the test performance characteristics of different methods of diagnosing hypertension in primary care.

The search strategy was based on the diagnostic filters developed by Haynes et $\mathrm{al}^{27}$ and Montori et al. ${ }^{28}$ To improve sensitivity in the search, ${ }^{29}$ however, we combined three separate search strategies using Medline and Embase (the full Medline search strategy is shown in appendix 2 on bmj.com): we combined keywords for hypertension, blood pressure monitoring, outpatient setting, and diagnosis; we limited MeSH terms for hypertension to diagnosis subheading and combined this with keywords for blood pressure monitoring and outpatient setting; and we combined keywords for hypertension, blood pressure monitoring, outpatient setting, and limit using the diagnosis search filter.

\section{Selection of studies}

Two reviewers ( $\mathrm{JH}$ and $\mathrm{RJMcM}$ ) independently reviewed the titles and abstracts of articles identified by the search strategy for potential relevance to the research question. After this process, the full papers of potentially eligible papers were assessed.

\section{Data management and extraction}

Two of four reviewers (JH, RJMcM, UM, JM) carried out data extraction from included papers in duplicate (the data extraction form template is in appendix 3 on bmj.com). Differences in data extraction were resolved by consensus. When necessary we contacted the authors of the primary studies to obtain additional information.

\section{Assessment of methodological quality}

We additionally collected information on recognised sources of bias in diagnostic test accuracy studies using a version of the QUADAS (Quality Assessment of Diagnostic Accuracy Studies) checklist, ${ }^{30}$ adapted for this study. The box lists the quality criteria considered.

\section{Data synthesis}

We extracted estimates of sensitivity and specificity from each study for all reported threshold combinations of clinic or home measurement and ambulatory measurement. We identified the subset of studies where the combined data shared the common reference threshold (ambulatory office monitoring 135/85 mm $\mathrm{Hg}$ ) and carried out a meta-analysis using hierarchical summary receiver operating characteristic (HSROC) models that accounted for sampling variability, unexplained heterogeneity, and covariation between sensitivity and specificity. ${ }^{29}$ Models were fitted to estimate and compare the sensitivity and specificity for diagnosis of hypertension made at the most common thresholds (140/90 mm Hg for clinic measurement, $135 / 85 \mathrm{~mm} \mathrm{Hg}$ for home measurement). Differences between the tests were expressed as relative sensitivities and specificities to ascertain if there was a significant difference in the relative performance of the tests compared with ambulatory measurement. In a final analysis all studies were included to explore the effect of different diagnostic thresholds. Models were fitted with the SAS Metadas code ${ }^{31}{ }^{32}$ and graphics produced with RevMan $5 .{ }^{33}$ When there were not enough studies available for fitting, we simplified the full models by assuming a symmetric receiver operating characteristic curve and fitting a fixed rather than random effects model. Sensitivity analyses considered the effect of differing the diagnostic thresholds, as 


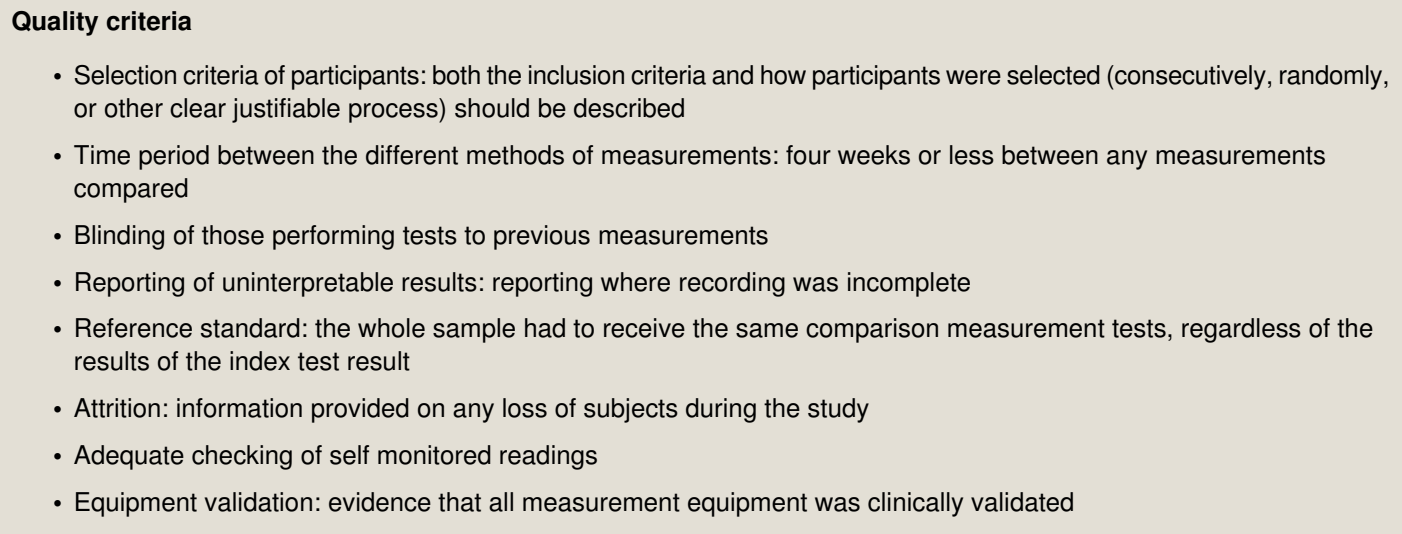

well as assessing test performance in populations with mean clinic blood pressure at or above the diagnostic threshold, to separately consider where study populations had been recruited entirely from a typical screening population (and so excluding any studies where an additional group of normotensive people were included as "controls"). Further analyses were planned with other population characteristics, methodological quality of the studies, and methods of monitoring.

\section{Results}

Our search identified 2914 studies (excluding duplicates), and we reviewed the full text of 115 papers for eligibility (fig 1). Of these, 20 contained extractable data; three were not written in English (one each in French, Spanish, and Dutch). The 20 studies included 5863 individuals with mean age of 48.8 and mean proportion of women of $57 \%$.

Table 1 gives details of the population of each study ${ }^{34-53}$ and table 2 gives details of their methodological quality. The studies differed markedly in terms of age (mean age ranged from $<33$ to 60 ), sex (percentage of men ranged from $16 \%$ to $69 \%$ ), sample size (from 16 to 2370), and whether a primary care or specialist population was used. All the studies had some degree of methodological weakness (or lack of clarity in what was reported): only 11 out of 20 studies used validated devices for all methods of monitoring, and only six provided evidence of blinding of those conducting the monitoring to previous blood pressure results. All studies avoided both partial and differential verification bias (that is, all patients in the studies received the same comparison measurement tests, regardless of initial results); reporting of attrition and selection criteria of participants was good.

There was marked diversity between studies in terms of mean baseline blood pressure of the population, number of measurements for clinic (2-18), home (18-56), and ambulatory monitoring (24-111), period of ambulatory measurement, and blood pressure thresholds used (tables 3 and 4). Similar diversity was seen in the range of sensitivity and specificity values for individual studies (tables 5 and 6). Two studies reported very low specificities: Denolle ${ }^{37}$ (specificity 0\%) and Elijovich et $\mathrm{al}^{38}$ $(18 \%)$, both of which had small sample sizes. The study by Denolle included a total sample of 16 patients, and none was normotensive according to both clinic and ambulatory classifications. In Elijovich et al, only three out of a total sample of 72 patients were normotensive according to both clinic and ambulatory classifications. ${ }^{38}$

We pooled studies with the same thresholds for the reference and index tests and included them in a meta-analysis. Eight studies used a threshold of $135 / 85 \mathrm{~mm} \mathrm{Hg}$ for ambulatory blood pressure monitoring and 140/90 $\mathrm{mm} \mathrm{Hg}$ for clinic blood pressure monitoring to diagnose hypertension, ${ }^{39} 434648-52$ while three used a threshold of 135/85 mm Hg for both ambulatory and home diagnosis. ${ }^{34} 3649$ One of the clinic comparison studies, ${ }^{39}$ however, used the mean of the full 24 hour ambulatory blood pressure monitoring rather than mean of daytime readings and was therefore not comparable with the others. Only one study provided proportions diagnosed as hypertensive using all three methods of blood pressure monitoring. ${ }^{49}$ Figure 2 provides forest plots of the sensitivity and specificity of eligible studies, with performance with either home or clinic measurement compared with ambulatory monitoring.

Figure 3 provides a summary receiver operating characteristic plot for the seven clinic comparison studies (mean age 47.1; mean proportion of women 57\%). Most studies were within the $95 \%$ confidence interval of the summary point, ${ }^{46} 48-5052$ or at least close to the receiver operating characteristic curve, ${ }^{51}$ showing some consistency in results across the studies. The remaining outlier study had a small sample size compared with the others, had a younger age profile with a lower mean blood pressure, and used an unvalidated monitor for clinic measurements. ${ }^{39}$

Figure 4 plots the three home comparison studies (mean age 52.5 ; mean proportion of women $55 \%$ ) on a summary receiver operating characteristic plot. Despite having quite different mean blood pressures and settings, two of the three studies were similar in terms of sensitivity and specificity. ${ }^{36}{ }^{49} \mathrm{With}$ so few studies in this group, however, we could not plot a confidence interval or assess the statistical homogeneity.

A receiver operating characteristic (ROC) curve for a single study shows the relation between the true positive rate (sensitivity) and the false positive rate (100-specificity) for different cut-off points. In a meta-analysis, the points represent different studies, and the fitted summary ROC curves depict trade-offs between sensitivity and specificity that arise because of differences between the studies. Where the studies combined have different thresholds, the pattern might reflect variation with threshold seen in a single study. Where the studies combined share a threshold, the pattern will reflect trade-offs caused by the other differences between the studies.

Table 7 shows the pooled sensitivity and specificity for home blood pressure measurement and clinic blood pressure measurement. Compared with ambulatory blood pressure monitoring of 135/85 mm Hg, clinic measurement over 140/90 $\mathrm{mm} \mathrm{Hg}$ had a mean sensitivity of $74.6 \%$ (95\% confidence interval $60.7 \%$ to $84.8 \%$ ) and specificity of $74.6 \%$ (47.9\% to $90.4 \%$ ), whereas home measurement over $135 / 85 \mathrm{~mm} \mathrm{Hg}$ had a mean sensitivity of $85.7 \%$ ( $78.0 \%$ to $91.0 \%$ ) and specificity of $62.4 \%$ (48.0\% to $75.0 \%)$. Neither the difference in sensitivity 
(relative sensitivity $1.15,0.95$ to 1.39$)$ nor specificity $(0.79$, 0.40 to 1.55 ) between the home and clinic measurements was significant.

We explored trade-offs between sensitivity and specificity with variation in blood pressure thresholds for home and clinic measurements (table 8). Increases in specificity and decreases in sensitivity with increasing threshold (and the converse for decreasing threshold) were significant for performance home measurements but not significant for the clinic measurements.

We could not carry out the planned sensitivity analyses evaluating methodological quality, population characteristics, or monitoring methods because of the small number of included studies. The removal of the outlying study, ${ }^{39}$ which used an unvalidated monitor, resulted in marginal changes (because of the small sample size of the excluded study) in sensitivity of clinic measurement from $74.6 \%(60.7 \%$ to $84.8 \%)$ to $72.6 \%$ $(56.7 \%$ to $84.2 \%)$ and in specificity from $74.6 \%$ (47.9\% to $90.4 \%$ ) to $77.9 \%$ (49.1\% to $92.8 \%$ ).

Sensitivity analysis of clinic comparisons including only those with mean blood pressures close to or above the diagnostic threshold found a sensitivity of $85.6 \%$ (81.0\% to $89.2 \%$ ) and specificity of $45.9 \%$ (33.0\% to $59.3 \%$ ) for clinic blood pressure. As all three included studies of home monitoring comparisons used a typical general practice screening population with no control group of normotensive people, we did not perform a further sensitivity analysis.

\section{Discussion}

\section{Summary of findings}

This review has shown that neither clinic nor home measurements of blood pressure are sufficiently specific or sensitive in the diagnosis of hypertension. We included 20 studies with 5683 patients that compared different methods of diagnosing hypertension in diverse populations with a range of thresholds applied. In the nine studies that used similar diagnostic thresholds and were included in the meta-analysis (two comparing home with ambulatory measurement only, six comparing clinic with ambulatory measurement only, and one study comparing all three methods), neither clinic nor home measurement could be unequivocally recommended as a single diagnostic test. Clinic measurement, the current reference in most clinical work and guidelines, performed poorly in comparison with ambulatory measurement, and, given that clinic measurements are also least predictive in terms of cardiovascular outcome, this is not reassuring for daily practice. ${ }^{10-12}{ }^{16-18}$ Home monitoring provided better sensitivity and might be suitable for ruling out hypertension given its relative ease of use and availability compared with ambulatory monitoring. In the case of clinic measurement, the removal of studies with a mean blood pressure in the normotensive range reduced specificity still further. This has profound implications for the management of hypertension, suggesting that ambulatory monitoring might lead to more appropriate targeting of treatment rather than starting patients on lifelong antihypertensive treatment on the basis of clinic measurements alone, as currently recommended. ${ }^{5}$ In clinical practice, this will be particularly important near the threshold for diagnosis, where most errors in categorisation will occur if ambulatory monitoring is not used.

\section{Strengths and limitations of study}

We used a comprehensive search strategy in multiple databases and all languages and are unlikely to have missed important numbers of relevant papers. While we did apply quality measures, we did not use a total measure of quality assessment to limit included papers as it is recognised that combining different shortcomings can generate distinct magnitudes of bias, even in opposing directions. ${ }^{29} 54$

The main weakness of our study is the paucity of data available. Only one study compared all three methods of measurement. Because of a lack of consensus internationally, a plethora of different thresholds was used, which meant that fewer than half of the studies could be combined in the meta-analysis.

The planned sensitivity analyses based on methodological quality, population characteristics, and monitoring schedule could not be performed because of the small number of studies and the methodological weaknesses inherent in included studies that would have made interpretation of such a subgroup analysis speculative. The number of measurements used, however, varied between two and 18 for clinic measurements (though only one study used more than six) compared with 18 to 42 for home measurements. These differences will have contributed to the observed heterogeneity and could explain the poor performance of clinic measurements, albeit that this is typical in clinical practice. The mean age of the population in the clinic comparison studies (47.1) was over five years younger than the mean age in the home comparison studies (52.5) and younger than a typical population of patients with hypertension in primary care (mid-60s). ${ }^{55}$

It was often not clear whether studies used validated measurement equipment, and even when it was mentioned, several studies provided validation citations on only some of the sphygmomanometers used. Given the shortage of literature on the subject, poor performance of a particular machine might conceivably lead to biased overall conclusions. We included in the meta-analysis only one study that used an unvalidated monitor, ${ }^{39}$ and exclusion of this study had a minimal effect on the results.

The findings clearly depend on the choice of the reference standard, and the three types of measurement are sufficiently different such that whichever one of them is chosen as the reference, the other two will perform relatively badly. The comparability of the performance of home monitoring to clinic measurement, rather than to ambulatory monitoring as might have been expected, could also reflect a relative paucity of relevant data, as there were only three home comparison studies, with wide confidence intervals for specificity (48\% to $75 \%$ ), with particularly poorly performance for home monitoring. Ambulatory monitoring, while providing the best correlation to outcome of the methods evaluated, nevertheless in general represents a single 24 hour period in an individual's life hence it is important that a "normal" day is chosen, typically a working day. A study of the long term reproducibility of ambulatory measurements taken three times over a two year period found that daytime ambulatory blood pressure provided a reproducible estimate in 54 people with borderline hypertension (correlation coefficient 0.70 for systolic blood pressure). ${ }^{56}$

Finally, we cannot consider the implications for clinical practice in terms of the best method of monitoring treatment effects as our research question focused solely on diagnostic studies.

\section{Comparisons with other studies}

We could not find a previous study that combined literature on the diagnosis of hypertension with different methods of measurement. Guidelines to date have tended to recommend the use of clinic measurement with ambulatory blood pressure monitoring and, to a lesser extent, home monitoring as secondary methods in special cases such as white coat hypertension..$^{5-9} 24$ 
Our results suggest that while this is a pragmatic approach supported by the results of treatment studies, more widespread use of ambulatory blood pressure monitoring for the diagnosis of hypertension, particularly around the thresholds, might result in more appropriately targeted treatment.

\section{Policy implications}

The poor specificity of both clinic and home measurement and poor sensitivity of clinic monitoring mean some people will be treated who would be defined as normotensive on the basis of ambulatory blood pressure monitoring. How big a proportion this is of the total number of people labelled as hypertensive will depend on the prevalence of hypertension in the population being studied. This can be seen in the sensitivity analysis where specificity drops as prevalence increases.

The positive and negative likelihood ratios were 2.07 and 0.25 for home compared with ambulatory measurement (across three comparison studies), respectively, and 2.94 and 0.34 for clinic compared with ambulatory measurement (across seven comparison studies), respectively. This suggests some correlation between the results of home or clinic measurement and ambulatory monitoring, but the correlation is not strong (positive likelihood ratios of over 10 and negative likelihood ratios of less than 0.1 would indicate a strong relation ${ }^{57}$ ). To help interpret this for clinical practice, ${ }^{58}$ if the prevalence of hypertension was as low as $10 \%$ (for example, in people under 40), then out of every four positive diagnoses provided by clinic measurement, close to three would be incorrect as judged by the reference standard of ambulatory measurement. If half of the population were hypertensive (such as those over 65), this would be reversed, and three out of every four positive diagnoses provided by clinic measurement would be correct with ambulatory measurement. When prevalence is $50 \%$, however, it might be more accurate to use the results of the sensitivity analysis where mean blood pressure in studies was close to or above the diagnostic threshold, and here only $61 \%$ of diagnoses after clinic measurements would be correct (table 9).

Many people with a current diagnosis of hypertension might not in fact have hypertension. This has important implications, both for the effect of labelling itself on otherwise healthy people ${ }^{59-62}$ and for the cost effectiveness of treatment. ${ }^{63}$ Perhaps an approach using clinic (or home) measurements as a screening test followed by ambulatory blood pressure monitoring for blood pressures that are within $10 \mathrm{~mm} \mathrm{Hg}$ of threshold might be appropriate before definitive treatment but arguably a wider use of ambulatory monitoring would be needed to avoid overtreatment of white coat hypertension as well as detection of masked cases.

As we did not have sufficient studies that used a high threshold, we cannot determine the relevance of ambulatory monitoring in people with high clinic readings. White coat hypertension, however, can manifest with very high clinic readings,${ }^{64}$ and, in the absence of a clinical indication for immediate treatment (such as the signs and symptoms of accelerated hypertension ${ }^{65}$ ), clinicians might want to organise an urgent ambulatory measurement rather than treat on the basis of limited clinic measurements.

\section{Conclusions}

Our study suggests that if ambulatory blood pressure monitoring is taken as the reference standard for the detection of hypertension, then treatment decisions based on clinic or home blood pressure alone, using thresholds of $140 / 90 \mathrm{~mm} \mathrm{Hg}$, result in substantial overdiagnosis. Ambulatory monitoring might lead to more appropriate targeting of treatment before the start of lifelong drug treatment, particularly around the diagnostic threshold. Considering the relative expense of ambulatory monitoring equipment, cost effectiveness analyses are essential before wholesale changes to the diagnosis of hypertension can be recommended.

Contributors: $\mathrm{CH}, \mathrm{FDRH}$, and RJMcM had the original idea and gained the funding. NR did the electronic searches; JH, RJMcM, JM, and UM extracted the data. BG, JH, and JJD undertook the analyses. All authors contributed to the manuscript and approved the final version. RJMcM is guarantor.

Funding: This work forms part of a larger programme on monitoring in primary care supported by the National Institute for Health Research. The views and opinions expressed are those of the authors and do not necessarily reflect those of the NHS, NIHR, or the Department of Health. RJMcM holds an NIHR career development fellowship.

Competing interests: All authors have completed the ICMJE uniform disclosure form at www.icmje.org/coi_disclosure.pdf (available on request from the corresponding author) and declare: no support from any organisation for the submitted work; no financial relationships with any organisations that might have an interest in the submitted work in the previous three years; no other relationships or activities that could appear to have influenced the submitted work.

Ethical approval: Not required.

Data sharing: Dataset available from the corresponding author at r.j.mcmanus@bham.ac.uk. The dataset includes only anonymised material already in the public domain.

Prospective Studies Collaboration. Age-specific relevance of usual BP to vascular mortality: a meta-analysis of individual data for one million adults in 61 prospective studies. Lancet 2002;360:1903-13.

2 Ezzati M, Lopez AD, Rodgers A, Vander Hoorn S, Murray CJ, for the Comparative Risk Assessment Collaborating Group. Selected major risk factors and global and regional burden of disease. Lancet 2002;360:1347-60.

3 Department of Health. Health survey for England 2003: trends. 2004. www.dh.gov.uk/ PublicationsAndStatistics/PublishedSurvey/HealthSurveyForEngland/HealthSurveyResults/ HealthSurveyResultsArticle/fs/en?CONTENT_ID=4098913\&chk=4DPdlh.

4 Information Centre for Health and Social Care. The quality and outcomes framework 2006/7. 2011. www.ic.nhs.uk/statistics-and-data-collections/audits-and-performance/thequality-and-outcomes-framework/the-quality-and-outcomes-framework-2006-07.

5 National Institute for Clinical Excellence. CG34 hypertension (persistently high blood pressure) in adults-NICE guideline. 2010. www.nice.org.uk/guidance/index.jsp? action $=$ byID\&o=10986.

6 Williams B, Poulter NR, Brown MJ, Davis M, McInnes GT, Potter JF, et al. Guidelines for management of hypertension: report of the fourth working party of the British Hypertension Society, 2004-BHS IV. J Hum Hypertens 2004;18:139-85.

7 National Heart, Blood, and Lung Institute. The seventh report of the joint national committee on prevention, detection, evaluation, and treatment of high blood pressure-complete report. 2004. www.nhlbi.nih.gov/guidelines/hypertension/jnc7full.htm.

8 National Collaborating Centre for Chronic Conditions. Hypertension: management in adults in primary care: pharmacological update. Royal College of Physicians, 2006.

9 Mancia G, De Backer G, Dominiczak A, Cifkova R, Fagard R, Germano G, et al. 2007 guidelines for the management of arterial hypertension: the Task Force for the Management of Arterial Hypertension of the European Society of Hypertension (ESH) and of the European Society of Cardiology (ESC). J Hypertens 2007;25:1105-87.

10 Onkubo T, Hozawa A, Nagai K, Kikuya M, Tsuji I, Ito S, et al. Prediction of stroke by ambulatory blood pressure monitoring versus screening blood pressure measurements in a general population: the Ohasama study. J Hypertens 2000;18:847-54.

11 Mancia G, Zanchetti A, Gabiti-Rosei E, Benemio G, De Cesaris R, Fogari R, et al. Ambulatory blood pressure is superior to clinic blood pressure in predicting treatment-induced regression of left ventricular hypertrophy. SAMPLE Study Group. Study on Ambulatory Monitoring of Blood Pressure and Lisinopril Evaluation. Circulation 1997;95:1464-70.

12 Verdecchia P. Prognostic value of ambulatory blood pressure: current evidence and clinical implications. Hypertension 2000;35:844-51.

13 Staessen JA, Thijs L, Fagard R, O'Brien ET, Clement D, de Leeuw PW, et al. Predicting cardiovascular risk using conventional vs ambulatory blood pressure in older patients with systolic hypertension. Systolic Hypertension in Europe Trial Investigators. JAMA 1999;282:539-46.

14 Fagard RH, Staessen JA, Thijs L. Prediction of cardiac structure and function by repeated clinic and ambulatory blood pressure. Hypertension 1997;29:22-9.

15 Imai Y, Ohkubo T, Sakuma M, Tsuji I, Satoh H, Nagai K, et al. Predictive power of screening blood pressure, ambulatory blood pressure and blood pressure measured at home for overall and cardiovascular mortality: a prospective observation in a cohort from Ohasama, northern Japan. Blood Press Monit 1996;1:251-4.

16 Whitworth JA, World Health Organization, International Society of Hypertension Writing Group. 2003 World Health Organization (WHO)/International Society of Hypertension (ISH) statement on management of hypertension. J Hypertens 2003;21:1983-92.

17 Verdecchia P. Reference values for ambulatory blood pressure and self-measured blood pressure based on prospective outcome data. Blood Pressure Monit 2001;6:323-7. 


\section{What is already known on this topic}

Hypertension is traditionally diagnosed after measurement of blood pressure in a clinic, but ambulatory and home measurements correlate better with outcome

\section{What this study adds}

Compared with ambulatory monitoring, neither clinic nor home measurements have sufficient sensitivity or specificity to be recommended as a single diagnostic test

If the prevalence of hypertension in a screened population was $30 \%$, there would only be a $56 \%$ chance that a positive diagnosis with clinic measurement would be correct compared with using ambulatory measurement

More widespread use of ambulatory blood pressure for the diagnosis of hypertension would result in more appropriately targeted treatment

18 Redon J, Campos C, Naciso ML, Rodico JL, Pascual JM, Ruilope LM. Prognostic value of ambulatory blood pressure monitoring in refractory hypertension: a prospective study. Hypertension 1998;31:712-8.

19 Mule G, Caimi G, Cottone S, Nardi E, Andronico G, Piazza G, et al. Value of home blood pressures as predictor of target organ damage in mild arterial hypertension. $J$ Cardiovasc Risk 2002;9:123-9.

20 Tsunoda S, Kawano Y, Horio T, Okuda N, Takishita S. Relationship between home blood pressure and longitudinal changes in target organ damage in treated hypertensive patients. Hypertens Res 2002;25:167-73.

21 Ohkubo T, Imai Y, Tsuji I, Nagai K, Kato J, Kikuchi N, et al. Home blood pressure measurement has a stronger predictive power for mortality than does screening blood pressure measurement: a population-based observation in Ohasama, Japan. $J$ Hypertens 1998;16:971-5.

22 Bobrie G, Genes N, Vaur L, Clerson P, Vaisse B, Mallion J-M, et al. Is "isolated home" hypertension as opposed to "isolated office" hypertension a sign of greater cardiovascular risk? Arch Intern Med 2001;161:2205-11.

23 Asayama K, Ohkubo T, Kikuya M, Metoki H, Obara T, Hoshi H, et al. Use of 2003 European Society of Hypertension-European Society of Cardiology guidelines for predicting stroke using self-measured blood pressure at home: the Ohasama study. Eur Heart J 2005;26:2026-31.

24 Mancia G, De Backer G, Dominiczak A, Cifkova R, Fagard R, Germano G, et al. Guidelines for the management of arterial hypertension: the Task Force for the Management of Arterial Hypertension of the European Society of Hypertension (ESH) and of the European Society of Cardiology (ESC). Eur Heart J 2007:28:1462-536.

25 Bray EP, Holder R, Mant J, McManus RJ. Does self-monitoring reduce blood pressure? Meta-analysis with meta-regression of randomized controlled trials. Ann Med 2010;42:371-86

26 Dolan E, Stanton A, Thijs L, Hinedi K, Atkins N, McClory S, et al. Superiority of ambulatory over clinic blood pressure measurement in predicting mortality: the Dublin outcome study. Hypertension 2005:46:156-61.

27 Haynes RB, Wilczynski NC, for the Hedges Team. Optimal search strategies for retrieving scientifically strong studies of diagnosis from Medline: analytical survey. BMJ 2004;328:1040.

28 Montori VM, Wilczynski NL, Morgan D, Haynes RB, for the Hedges Team. Optimal search strategies for retrieving systematic reviews from Medline: analytical survey. BMJ 2005;330:68.

29 Leeflang MMG, Deeks JJ, Gatsonis C, Bossuyt PMM, for the Cochrane Diagnostic Test Accuracy Working Group. Systematic reviews of diagnostic test accuracy. Ann Intern Med 2008;149:889-97.

30 Whiting P, Rutjes AWS, Reitsma JB, Bossuyt PMM, Kleijnen J. The development of QUADAS: a tool for the quality assessment of studies of diagnostic accuracy included in systematic reviews. BMC Med Res Methodol 2003:3:25.

31 Dinnes J, Deeks JJ, Kirby J, Roderick P. A methodological review of how heterogeneity has been examined in systematic reviews of diagnostic test accuracy. Health Technol Assess 2005;9:12.

32 Takwoingi $Y$, Guo B, Deeks JJ. Metadas: an SAS macro for meta-analysis of diagnostic accuracy studies. In: Deeks JJ, Glasziou P, Irwig L, eds. Methods for evaluating medical tests symposium. University of Birmingham, 2008.

33 Nordic Cochrane Centre. Review Manager (RevMan) [computer program]. Version 5.0. Cochrane Collaboration, 2008

34 Bayo J, Cos FX, Roca C, Dalfo A, Martin-Baranera MM, Albert B. Home blood pressure self-monitoring: diagnostic performance in white-coat hypertension. Blood Pressure Monit 2006;11:47-52.

35 Brueren MM, Dinant GJ, Schouten BJ, van-Ree JW. Hypertensiediagnostiek door de huisarts: metingen volgens de NHG-standaard vergeleken met ambulante bloeddrukmeting Ned Tijdschr Geneeskd 1995;139:278-82.

36 Den Hond E, Celis H, Fagard R, Keary L, Leeman M, O'Brien E, et al. Self-measured versus ambulatory blood pressure in the diagnosis of hypertension. $J$ Hypertens 2003;21:717-22.

37 Denolle T. Comparaison et reproductibilite de 4 methodes de mesure indirect de la pression arterielle dans l'hypertension arterielle legere. Arch Mal Coeur Vaiss 1995:88:1165-70.

38 Elijovich F, Laffer CL. Bayesian analysis supports use of ambulatory blood pressure monitors for screening. Hypertension 1992;19:268-72.

39 Flores L, Recasens M, Gomis R, Esmatjes E. White coat hypertension in type 1 diabetic patients without nephropathy. Am J Hypertens 2000;13:560-3.

40 Gourlay SG, McNeil JJ, Marriner T, Farish SJ, Prijatmoko D, McGrath BP. Discordance of mercury sphygmomanometer and ambulatory blood pressure measurements for the detection of untreated hypertension in a population study. J Hum Hypertens 1993;7:467-72.

41 Hoegholm A, Kristensen KS, Madsen NH, Svendsen TL. The frequency of white coat hypertension among patients with newly diagnosed hypertension. Cardiovasc Rev Rep 1994;15:55-61.
42 Imai Y, Tsuji I, Nagai K, Sakuma M, Ohkubo T, Watanabe N, et al. Ambulatory blood pressure monitoring in evaluating the prevalence of hypertension in adults in Ohasama, a rural Japanese community. Hypertens Res 1996;19:207-12.

43 Larkin KT, Schauss SL, Elnicki DM. Isolated clinic hypertension and normotension: false positives and false negatives in the assessment of hypertension. Blood Pressure Monit 1998;3:247-54.

44 Llibre JB, Saumell CR, Baque AD, Martin-Baranera MM, Tona KXN, Puig AB. Automedida de la presion arterial domiciliaria. Influencia del sistema de calculo de la media en el diagnostico de la hipertension de bata blanca. Atencion Primaria 2006;38:212-8.

45 Modesti PA, Pieri F, Cecioni I, Valenti R, Mininni S, Toccafondi S, et al. Comparison of ambulatory blood pressure monitoring and conventional office measurement in the workers of a chemical company. Int J Cardiol 1994:46:151-7.

46 Ogedegbe G, Pickering TG, Clemow L, Chaplin W, Spruill TM, Albanese GM, et al. The misdiagnosis of hypertension. Arch Intern Med 2008;168:2459-65.

47 Ozdemir FN, Guz G, Sezer S, Arat Z, Haberal M. Ambulatory blood pressure monitoring in potential renal transplant donors. Nephrol Dial Transplant 2000;15:1038-40.

48 Shimbo D, Kuruvilla S, Haas D, Pickering TG, Schwartz JE, Gerin W. Preventing misdiagnosis of ambulatory hypertension: algorithm using office and home blood pressures. $J$ Hypertens 2009;27:1775-83.

49 Stergiou GS, Skeva II, Baibas NM, Kalkana CB, Roussias LG, Mountokalakis TD. Diagnosis of hypertension using home or ambulatory blood pressure monitoring: comparison with the conventional strategy based on repeated clinic blood pressure measurements. J Hypertens 2000;18:1745-51.

50 Stergiou GS, Salgami EV, Tzamouranis DG, Roussias, LG. Masked hypertension assessed by ambulatory blood pressure versus home blood pressure monitoring: is it the same phenomenon? Am J Hypertens 2005;18:772-8.

51 Trudel X, Brisson C, Larocque B, Milot A. Masked hypertension: different blood pressure measurement methodology and risk factors in a working population. $J$ Hypertens 2009;27:1560-7.

52 Ungar A, Pepe G, Monami M, Lambertucci L, Torrini M, Baldasseroni S, et al. Isolated ambulatory hypertension is common in outpatients referred to a hypertension center. $J$ Hum Hypertens 2004;18:897-903.

53 Zabludowski JR, Rosenfeld JB. Evaluation of clinic blood pressure measurements: assessment by daytime ambulatory blood pressure monitoring. Isr J Med Sci 1992;28:345-8.

54 Egger M, Jüni P, Bartlett C, Holenstein F, Sterne J. How important are comprehensive literature searches and the assessment of trial quality in systematic reviews? Empirical study. Health Technol Assess 2003;7:1.

55 McManus RJ, Mant J, Bray EP, Holder R, Jones MI, Greenfield S, et al. Telemonitoring and self-management in the control of hypertension (TASMINH2): a randomised controlled trial. Lancet 2010;376:163-72.

56 Asagami T, Kushiro T, Inoue J, Kanmatsuse K. Long-term reproducibility and usefulness of daytime recording of noninvasive 24-hour ambulatory blood pressure monitoring in borderline hypertension: a two-year follow-up study. Clin Exp Hypertens 1996;18:637-57.

57 Deeks JJ, Altman DG. Diagnostic tests 4: likelihood ratios. BMJ 2004;329:168-9.

58 Perera R, Heneghan C. Making sense of diagnostic tests likelihood ratios. Evid Based Med 2006;11:130-1.

59 Haynes RB, Sackett DL, Taylor DW, Gibson ES, Johnson AL. Increased absenteeism from work after detection and labelling of hypertensive patients. $N$ Engl J Med 1978;299:741-4.

60 Macdonald LA, Sackett DL, Haynes RB, Taylor RW. Labelling in hypertension: a review of the behavioural and psychological consequences. J Chronic Dis 1984;37:933-42.

61 Johnstone ME, Gibson ES, Terry CW, Haynes RB, Taylor DW, Gafni A, et al. Effects of labelling on income work and social function among hypertensive employees. J Chron Dis 1984;37:417-23.

62 Bloom JR, Monterossa S. Hypertension labelling and sense of well-being. A J Public Health 1981;71:1228-32.

63 Montgomery AA, Fahey T, Ben-Shlomo Y, Harding J. The influence of absolute cardiovascular risk, patient utilities, and costs on the decision to treat hypertension: a Markov decision analysis. J Hypertens 2003:21:1753-9.

64 Myers MG, Godwin M, Dawes M, Kiss A, Tobe SW, Grant FC, et al. Conventional versus automated measurement of blood pressure in primary care patients with systolic hypertension: randomised parallel design controlled trial. BMJ 2011;342:d286.

65 Vaziri ND. Malignant or accelerated hypertension. West J Med 1984;140:575-82.

Accepted: 17 April 2011 


\section{Tables}

\begin{tabular}{|c|c|c|c|c|c|}
\hline Study & Comparison group* & Sample size & $\begin{array}{c}\text { Mean (SD if available) } \\
\text { age (years) } \dagger\end{array}$ & $\%$ Men‡ & Study population§ \\
\hline Bayo $2006^{34}$ & Home & 181 & 58.4 & 41 & Primary care at risk \\
\hline Brueren $1995^{35}$ & Clinic & 94 & 47 & 52 & Primary care at risk \\
\hline Den Hond $2003^{36}$ & Home & 247 & $50.4(11.0)$ & 46 & Primary care \\
\hline Denolle $1995^{37}$ & Home/Clinic & 16 & $45(11)$ & 69 & Secondary care \\
\hline Elijovich $1992^{38}$ & Clinic & 72 & $58.5(1.6)$ & 16 & Secondary care \\
\hline Flores $2000^{39}$ & Clinic & 47 & 32.7 & 57 & Secondary care \\
\hline Gourlay $1993^{40}$ & Clinic & 66 & 45 & 62 & General population \\
\hline Hoegholm $1994^{41}$ & Clinic & 153 & 47.4 & 46 & Secondary care \\
\hline Imai $1996^{42}$ & Clinic & 684 & $56.3(12.0)$ & 31 & General population \\
\hline Larkin $1998^{43}$ & Home/Clinic & 65 & $45.1(12.5)$ & 52 & Community volunteers \\
\hline Llibre $2006^{44}$ & Home & 156 & $57.6(12)$ & 42 & Primary care at risk \\
\hline Modesti $1994^{45}$ & Clinic & 139 & $38.7(9.8)$ & 62 & General population \\
\hline Ogedegbe $2008^{46}$ & Clinic & 238 & 51.7 & 48 & General population/At risk \\
\hline Ozdemir $2000^{47}$ & Clinic & 126 & $45.0(12.4)$ & 52 & Secondary care \\
\hline Shimbo $2009^{48}$ & Clinic & 229 & $52.5(14.6)$ & 46 & General population/At risk \\
\hline Stergiou $2000^{49}$ & Home/Clinic & 133 & $48.4(10.2)$ & 55 & Secondary care \\
\hline Stergiou $2005^{50} \S$ & Clinic & 288 & $48.5(11.0)$ & 61 & Secondary care \\
\hline Trudel $2009^{51}$ & Clinic & 2370 & 44 & 39 & General population \\
\hline Ungar $2004^{52}$ & Clinic & 388 & $60(15)$ & 49 & Secondary care \\
\hline Zabludowski $1992^{53}$ & Clinic & 171 & 48.0 & 33 & Secondary care \\
\hline
\end{tabular}

${ }^{*}$ Stergio ${ }^{50}$ included self monitoring arm but was study of masked hypertension defined with clinic measurement so results of home monitoring usable only in comparison with clinic monitoring arm and not in comparison with results of ambulatory measurements.

†In Flores ${ }^{39}$ age 30.8 (7.9) in 20 normotensive people, 32.8 (7.2) in 20 with white coat hypertension, and 37.8 (7.8) in 7 with hypertension. In Hoegholm ${ }^{41}$ age range 17-76, median 47; mean (SD) 48.0 (1.1) in those with ambulatory hypertension, 46.4 (1.8) in ambulatory normotensive people. In Ogedegbe ${ }^{46}$ age 45.9 in normotensive people, 56.3 in white coat hypertension, 56.0 in sustained hypertension, 52.2 in masked hypertension. In Zabludowski ${ }^{53}$ age 48 in those with clinic and ambulatory hypertension, 51 in clinic hypertension and ambulatory normotension, 47 in clinic normotension and ambulatory hypertension, 45 in clinic and ambulatory normotension.

¥In Imai ${ }^{42}$ percentage male is taken from whole sample, including treated and untreated patients.

$\S$ In Ogedegbe ${ }^{46}$ sample drawn from physician referrals to hypertension centre in hospital and through media advertisements. In Shimbo ${ }^{48}$ people with hypertension recruited from hypertension centre in hospital and medical centre. Normotensive people recruited through advertisements. Trudel ${ }^{51}$ included white collar workers from three public insurance institutions. 
Table 2| Methodological quality ${ }^{*}$ of included studies of methods of measuring blood pressure compared with ambulatory monitoring in diagnosis of hypertension

\begin{tabular}{|c|c|c|c|c|c|c|c|c|c|}
\hline Study & Selection & $\begin{array}{c}\text { Measurement } \\
\text { times }\end{array}$ & Replication & Blinding & Reporting & $\begin{array}{l}\text { Reference } \\
\text { standard }\end{array}$ & Attrition & Checking & $\begin{array}{c}\text { Equipment } \\
\text { validation }\end{array}$ \\
\hline Bayo $2006^{34}$ & $Y$ & $\mathrm{~N}$ & $Y$ & $Y$ & $\mathrm{~N}$ & $Y$ & Y & Y & $Y$ \\
\hline Brueren $1995^{35}$ & $\mathrm{Y}$ & $\mathrm{N}$ & Y & $\mathrm{Y}$ & $\mathrm{N}$ & $\mathrm{Y}$ & $\mathrm{Y}$ & NA & $\mathrm{Y}$ \\
\hline Den Hond $2003^{36}$ & $\mathrm{Y}$ & $\mathrm{Y}$ & $Y$ & $\mathrm{~N}$ & $\mathrm{~N}$ & $\mathrm{Y}$ & $Y$ & $Y$ & $\mathrm{Y}$ \\
\hline Denolle $1995^{37}$ & $\mathrm{Y}$ & $Y$ & $\mathrm{~N}$ & $\mathrm{~N}$ & $\mathrm{~N}$ & $\mathrm{Y}$ & $\mathrm{Y}$ & $\mathrm{Y}$ & $\mathrm{N}$ \\
\hline Elijovich $1992^{38}$ & $\mathrm{~N}$ & $\mathrm{Y}$ & $\mathrm{N}$ & $\mathrm{N}$ & $\mathrm{N}$ & $\mathrm{Y}$ & $\mathrm{Y}$ & NA & $\mathrm{N}$ \\
\hline Flores $2000^{39}$ & $\mathrm{Y}$ & $\mathrm{N}$ & $\mathrm{N}$ & $\mathrm{N}$ & $\mathrm{N}$ & $\mathrm{Y}$ & $\mathrm{Y}$ & NA & $\mathrm{N}$ \\
\hline Gourlay $1993^{40}$ & $Y$ & $\mathrm{~N}$ & $Y$ & $Y$ & $\mathrm{~N}$ & $\mathrm{Y}$ & $\mathrm{Y}$ & NA & $\mathrm{N}$ \\
\hline Hoegholm $1994^{41}$ & $\mathrm{Y}$ & $\mathrm{Y}$ & $\mathrm{Y}$ & $\mathrm{N}$ & $\mathrm{N}$ & $\mathrm{Y}$ & $\mathrm{N}$ & NA & $\mathrm{N}$ \\
\hline Imai $1996^{42}$ & $Y$ & $\mathrm{~N}$ & $\mathrm{~N}$ & $\mathrm{~N}$ & $\mathrm{~N}$ & $Y$ & $Y$ & NA & $\mathrm{N}$ \\
\hline Larkin $1998^{43}$ & $Y$ & $Y$ & $\mathrm{Y}$ & $\mathrm{N}$ & $\mathrm{N}$ & $\mathrm{Y}$ & $\mathrm{Y}$ & $\mathrm{N}$ & $\mathrm{N}$ \\
\hline Llibre $2006^{44}$ & $\mathrm{Y}$ & $\mathrm{Y}$ & $\mathrm{N}$ & $\mathrm{Y}$ & $\mathrm{N}$ & $\mathrm{Y}$ & $\mathrm{N}$ & $Y$ & $\mathrm{Y}$ \\
\hline Modesti $1994^{45}$ & $\mathrm{Y}$ & $\mathrm{N}$ & $Y$ & $\mathrm{~N}$ & $\mathrm{~N}$ & $\mathrm{Y}$ & $Y$ & NA & $\mathrm{Y}$ \\
\hline Ogedegbe $2008^{46}$ & $Y$ & $Y$ & $\mathrm{~N}$ & $Y$ & $\mathrm{~N}$ & $Y$ & $\mathrm{~N}$ & NA & $Y$ \\
\hline Ozdemir $2000^{47}$ & $\mathrm{~N}$ & $\mathrm{Y}$ & $\mathrm{N}$ & $\mathrm{N}$ & $\mathrm{N}$ & $\mathrm{Y}$ & $\mathrm{Y}$ & NA & $\mathrm{N}$ \\
\hline Shimbo $2009^{48}$ & $Y$ & $Y$ & $Y$ & $Y$ & $\mathrm{~N}$ & $\mathrm{Y}$ & $Y$ & NA & $Y$ \\
\hline Stergiou $2000^{49}$ & $\mathrm{~N}$ & $Y$ & $Y$ & $\mathrm{~N}$ & $\mathrm{~N}$ & $\mathrm{Y}$ & $\mathrm{Y}$ & $\mathrm{N}$ & $\mathrm{Y}$ \\
\hline Stergiou $2005^{50}$ & $\mathrm{~N}$ & $\mathrm{Y}$ & $Y$ & $\mathrm{~N}$ & $\mathrm{~N}$ & Y & Y & $\mathrm{Y}$ & $\mathrm{Y}$ \\
\hline Trudel $2009^{51}$ & $Y$ & $Y$ & $\mathrm{~N}$ & $\mathrm{~N}$ & $\mathrm{~N}$ & $\mathrm{Y}$ & $\mathrm{N}$ & NA & $Y$ \\
\hline Ungar $2004^{52}$ & $Y$ & $\mathrm{Y}$ & $Y$ & $\mathrm{~N}$ & $\mathrm{~N}$ & $\mathrm{Y}$ & $Y$ & NA & $Y$ \\
\hline Zabludowski $1992^{53}$ & $Y$ & $Y$ & $\mathrm{~N}$ & $\mathrm{~N}$ & $Y$ & $\mathrm{Y}$ & $Y$ & NA & $\mathrm{N}$ \\
\hline
\end{tabular}

$\mathrm{NA}=$ not applicable.

*Selection=clear selection criteria; measurement times=adequate and clear time period between measurements; replication=sufficient detail to permit replication of test; blinding=blinding of those performing tests to previous monitoring results; reporting=reporting of uninterpretable test results; reference standard=same reference standard used across sample; attrition=information on attrition; checking=adequate checking of self monitoring readings; equipment validation=all measurement kit validated or not. 
Table 3 | Description of methods in studies of ambulatory monitoring compared with clinic monitoring of blood pressure in diagnosis of hypertension

\begin{tabular}{|c|c|c|c|c|c|}
\hline \multirow[b]{2}{*}{ Study } & \multirow{2}{*}{$\begin{array}{l}\text { Period of ambulatory } \\
\text { measurement }\end{array}$} & \multicolumn{2}{|c|}{ No of measurements* } & \multicolumn{2}{|c|}{ Mean blood pressure $(\mathrm{mm} \mathrm{Hg}) \dagger$} \\
\hline & & Ambulatory & Clinic & Ambulatory & Clinic \\
\hline Brueren $1995^{35}$ & Day (06:00-22:00) & 64 & 10 or 6 & NA & 102.6 (diastolic) \\
\hline Denolle1995 ${ }^{37}$ & 22 hours & $79(9) \S$ & 3 & $131 / 89$ & $156 / 91$ \\
\hline Elijovich $1992^{38}$ & Day (06:00-24:00) & 36 & 3 & $151 / 94$ & $168 / 101$ \\
\hline Flores $2000^{39}$ & Day (08:00-22:00) & 42 (daytime) & 3 & $124.1 / 76.2$ & $136.2 / 84.8$ \\
\hline Gourlay $1993^{40}$ & Day (10:00-22:00) & 24 (daytime) & 2 & $131 / 76$ & $132 / 83$ \\
\hline Hoegholm $1994^{41}$ & Day (07:00-23:00) & 64 (daytime) & 5 & $145.2 / 95.9$ & $156.8 / 99.8$ \\
\hline Imai $1996^{42}$ & 24 hours & $46.5(3.8) \S$ & 2 & $120 / 71$ & $126 / 72$ \\
\hline Larkin $1998^{43}$ & 24 hours & Max 48, mean 45 & 9 & $132.8 / 81.9$ & $127.8 / 82.7$ \\
\hline Modesti $1994^{45}$ & Day (07:00-22:00) & 60 & 2 & $120 / 75$ & $129 / 85$ \\
\hline Ogedegbe $2008^{46}$ & Day (awake) & Unclear & up to 18 & $129.6 / 77.9$ & $129.3 / 77.8$ \\
\hline Ozdemir $2000^{47}$ & 24 hours & 111 & 3 & NA & NA \\
\hline Shimbo $2009^{48}$ & Day (awake) & $33.4(11.8) \ddagger$ & 6 & $135 / 83$ & $133.5 / 83$ \\
\hline Stergiou $2000^{49}$ & Day (awake) & 102 & 2 & $139.3 / 91.1$ & $143.2 / 93.0$ \\
\hline Stergiou $2005^{50}$ & Day (awake) & 51 & 4 & $140.8 / 91.3$ & $144.7 / 94.2$ \\
\hline Trudel $2009^{51}$ & Working hours & $>20$ (c28-32) & 3 & $123.9 / 79.2$ & $122.6 / 76.2$ \\
\hline Ungar $2004^{52}$ & Day (07:00-22:00) & 60 (day) & 4 to 6 & $141 / 86$ & $151 / 93$ \\
\hline Zabludowski $1992^{53}$ & Day (06:00-24:00) & 72 (day) & 3 & $150.5 / 85.4$ & $158.9 / 90.6$ \\
\hline
\end{tabular}

$\mathrm{NA}=$ not available.

*In Brueren ${ }^{35} 10$ or 6 depending on initial office reading (interpreted as baseline for inclusion not test). In Larkin ${ }^{43}$ maximum was 48 over $24 \mathrm{~h}$ period but mean was 45. In Ogedegbe ${ }^{46}$ measurements taken every 15 minutes until 22:00 and every hour between 22:00 and 06:00 next morning. In Ozdemir ${ }^{47}$ taken every 10 min during day (06:00-23:00) and every 45 min through night (23:00-06:00). Stergiou ${ }^{49}$ used average (for instance 2nd and 3rd measurement) of fifth and final visit for clinic measurement; $02: 00$ and 14:00 for monitoring days 2-6 for home measurement; every 20 min for $24 \mathrm{~h}$ on 2 days for ambulatory measurement, so max is 144 measurements but only awake is used, so 102 would be pragmatic average. Stergiou ${ }^{50}$ used 3 readings/h over $24 \mathrm{~h}$ period (max 72 ), but only awake readings used (patients with less than 30 valid readings excluded); pragmatic average 51 readings with 7 hours of sleep assumed. Trudel ${ }^{51}$ required at least 20 ambulatory measurements; 4 taken every hour during working hours. For clinic, Ungar ${ }^{52}$ used 2 measurements taken on 2 separate occasions, but on each occasion 3 rd measurement was taken if first 2 differed by more than $5 \mathrm{~mm} \mathrm{Hg}$

†In Brueren ${ }^{35}$ for clinic measurement mean blood pressure was 107.7 in 30 and 100.2 in 64 . In Flores ${ }^{39}$ clinic normotension was $124.7 / 74.5$, white coat hypertension was 146.1/92.5, hypertension was 140.8/92.0; daytime normotension was 118.6/73.2, hypertension was 138.8/80.2, white coat hypertension was 124.5/77.8. In Hoegholm ${ }^{41} \mathrm{n}=153$ for clinic, 159 for daytime ambulatory. In Zabludowski ${ }^{53}$ ambulatory blood pressure: 160/95 for clinic and ambulatory hypertension; $141 / 77$ for clinic hypertension, ambulatory normotension: 163/93 for clinic normotension, ambulatory hypertension; $142 / 77$ for clinic and ambulatory normotension. Clinic blood pressure: $165 / 100$ for clinic and ambulatory hypertension; $160 / 94$ for clinic hypertension, ambulatory normotension; 151/77 for clinic normotension, ambulatory hypertension; 151/77 for clinic and ambulatory normotension.

$\ddagger$ Mean (SD). 
Table 4| Description of methods in studies of ambulatory monitoring compared with home monitoring of blood pressure

\begin{tabular}{|c|c|c|c|c|c|}
\hline \multirow[b]{2}{*}{ Study } & \multirow{2}{*}{$\begin{array}{l}\text { Period of ambulatory } \\
\text { measurement }\end{array}$} & \multicolumn{2}{|c|}{ No of measurements ${ }^{*}$} & \multicolumn{2}{|c|}{ Mean blood pressure $(\mathrm{mm} \mathrm{Hg}) \dagger$} \\
\hline & & Ambulatory & Home & Ambulatory & Home \\
\hline Bayo $2006^{34}$ & Day (07:00-23:00) & 48 & 18 & $134.8 / 81.3$ & $137.4 / 82.1$ \\
\hline Den Hond $2003^{36}$ & Day (08:00-22:00) & 40 & 42 & $148.1 / 95.0$ & $143.1 / 91.5$ \\
\hline Denolle $1995^{37}$ & 22 hours & $79(9) \ddagger$ & $29(2) \ddagger$ & $131 / 89$ & $128 / 87$ \\
\hline Larkin $1998^{43}$ & 24 hours & $45(\max 48)$ & 56 & $132.8 / 81.9$ & $131.4 / 80.0$ \\
\hline Llibre $2006^{44}$ & Day (07:00-23:00) & 48 & 18 & $134.8 / 81.6$ & $136.9 / 82.1$ \\
\hline Stergiou $2000^{49}$ & Day (awake) & 102 & 20 & 139.3/91.1 & $138.7 / 89.3$ \\
\hline
\end{tabular}

${ }^{*}$ Larkin $^{43}$ maximum was 48 over $24 \mathrm{~h}$ period but mean was 45 . Llibre ${ }^{44} 48$ day or 64 all day (unclear which used). Stergiou ${ }^{49}$ clinic $=$ average (that is, 2 nd and $3 r d$ measurement) of 5th and final visit; home $=02: 00$ and 14:00 for monitoring days 2-6; ambulatory=every $20 \mathrm{~min}$ for $24 \mathrm{~h}$ for 2 days, so max is 144 measurements but only awake is used, so 102 would be pragmatic average.

†Den $\mathrm{Hond}^{36}$ home mean also reported as 142.4/91.0 in graph but reading in table accepted as primary result. Llibre ${ }^{44}$ daytime: 134.8/81.6; 24 h: 130.4/78.0 $\neq$ Mean (SD). 


\begin{tabular}{|c|c|c|c|c|c|c|}
\hline \multirow[b]{2}{*}{ Study } & \multicolumn{2}{|c|}{ Diagnostic thresholds $(\mathrm{mm} \mathrm{Hg})^{*}$} & \multirow{2}{*}{$\begin{array}{l}\text { Sensitivity \% (95\% } \\
\text { Cl) }\end{array}$} & \multirow{2}{*}{$\begin{array}{l}\text { Specificity } \%(95 \% \\
\text { Cl) }\end{array}$} & \multicolumn{2}{|c|}{ Likelihood ratio $(95 \% \mathrm{Cl})$} \\
\hline & Ambulatory & Clinic & & & Positive & Negative \\
\hline Brueren $1995^{35}$ & 91 (diastolic) & 95 (diastolic) & 67 (52 to 80$)$ & 52 (37 to 67$)$ & 1.39 (0.97 to 2.00$)$ & $0.64(0.39$ to 1.04$)$ \\
\hline Brueren $1995^{35}$ & 91 (diastolic) & 105 (diastolic) & 29 (17 to 44$)$ & 98 (88 to 100$)$ & 13.42 (1.84 to 97.96$)$ & $0.72(0.60$ to 0.87$)$ \\
\hline Denolle $1995^{37}$ & $139 / 87$ & $140 / 90$ & 64 (31 to 89$)$ & $0(0$ to 52$)$ & $0.64(0.41$ to 1.00$)$ & 0 \\
\hline Elijovich $1992^{38}$ & $139 / 88$ & $140 / 90$ & 89 (78 to 96$)$ & $18(4$ to 43$)$ & 1.08 (0.85 to 1.37$)$ & $0.62(0.17$ to 2.21$)$ \\
\hline Flores $2000^{39}$ & $135 / 85$ & $140 / 90$ & 100 (59 to 100$)$ & 50 (34 to 66$)$ & 2.00 (1.47 to 2.73$)$ & 0 \\
\hline Gourlay $1993^{40}$ & $135 / 85$ & $150 / 90$ & 74 (49 to 91$)$ & 87 (74 to 95$)$ & 5.77 (2.61 to 12.77$)$ & $0.30(0.14$ to 0.65$)$ \\
\hline Gourlay $1993^{40}$ & $135 / 85$ & $160 / 95$ & 47 (24 to 71$)$ & 94 (82 to 99$)$ & 7.42 (2.25 to 24.47$)$ & 0.56 (0.37 to 0.87$)$ \\
\hline Hoegholm $1994^{41}$ & 90 (diastolic) & 90 (diastolic) & 95 (89 to 98 ) & $43(29$ to 57$)$ & 1.65 (1.31 to 2.09 ) & $0.12(0.05$ to 0.29$)$ \\
\hline Imai $1996^{42}$ & $133 / 78$ & $140 / 90$ & 42 (33 to 51$)$ & $88(84$ to 90$)$ & 3.36 (2.50 to 4.54$)$ & 0.66 (0.57 to 0.77$)$ \\
\hline Imai $1996^{42}$ & $144 / 85$ & $140 / 90$ & 58 (42 to 73 ) & 85 (82 to 87 ) & $3.76(2.76$ to 5.14$)$ & $0.50(0.35$ to 0.71$)$ \\
\hline Imai $1996^{42}$ & $133 / 78$ & $160 / 95$ & 17 (11 to 24$)$ & 98 (96 to 99 ) & 7.74 (3.93 to 15.23$)$ & 0.85 (0.79 to 0.92$)$ \\
\hline Imai $1996^{42}$ & $144 / 85$ & $160 / 95$ & 33 (19 to 49$)$ & 97 (95 to 98$)$ & 10.43 (5.67 to 19.19$)$ & 0.70 (0.57 to 0.86$)$ \\
\hline Larkin $1998^{43}$ & $140 / 90$ & $140 / 90$ & 52 (31 to 72$)$ & 78 (62 to 89$)$ & 2.31 (1.16 to 4.60$)$ & $0.62(0.40$ to 0.96$)$ \\
\hline Larkin $1998^{43}$ & $135 / 85$ & $140 / 90$ & 50 (33 to 67$)$ & 86 (68 to 96$)$ & 3.63 (1.38 to 9.53$)$ & 0.58 (0.41 to 0.83 ) \\
\hline Larkin $1998^{43}$ & See notes ${ }^{*}$ & $140 / 90$ & 53 (35 to 71$)$ & 85 (68 to 95$)$ & 3.51 (1.47 to 8.37$)$ & 0.55 (0.37 to 0.82$)$ \\
\hline Modesti $1994^{45}$ & See notes ${ }^{*}$ & 90 (diastolic) & 80 (56 to 94$)$ & 84 (76 to 90$)$ & 5.01 (3.14 to 7.99 ) & $0.24(0.10$ to 0.57$)$ \\
\hline Ogedegbe $2008^{46}$ & $135 / 85$ & $140 / 90$ & 68 (59 to 76 ) & 81 (72 to 88$)$ & 3.55 (2.35 to 5.36$)$ & $0.40(0.31$ to 0.52$)$ \\
\hline Ozdemir $2000^{47}$ & See notes ${ }^{*}$ & $140 / 90$ & 80 (61 to 92$)$ & 86 (78 to 93 ) & 5.91 (3.46 to 10.10$)$ & $0.23(0.11$ to 0.48$)$ \\
\hline Shimbo $2009^{48}$ & $135 / 85$ & $140 / 90$ & 57 (48 to 65$)$ & 91 (83 to 96$)$ & 6.12 (3.23 to 11.61$)$ & $0.48(0.39$ to 0.59$)$ \\
\hline Stergiou $2000^{49}$ & $140 / 90$ & $140 / 90$ & 86 (76 to 92$)$ & 54 (39 to 68$)$ & 1.86 (1.36 to 2.54$)$ & $0.27(0.15$ to 0.48$)$ \\
\hline Stergiou $2000^{49}$ & $135 / 85$ & $140 / 90$ & 81 (72 to 88 ) & 63 (44 to 79 ) & 2.17 (1.37 to 3.42$)$ & $0.30(0.19$ to 0.49$)$ \\
\hline Stergiou $2005^{50}$ & $135 / 85$ & $140 / 90$ & $86(80$ to 90$)$ & 45 (32 to 58$)$ & 1.56 (1.23 to 1.97$)$ & $0.32(0.21$ to 0.49$)$ \\
\hline Trudel $2009^{51}$ & $135 / 85$ & $140 / 90$ & 38 (34 to 42 ) & 98 (97 to 99$)$ & 21.46 (14.99 to 30.72 ) & 0.63 (0.59 to 0.67$)$ \\
\hline Ungar $2004^{52}$ & $135 / 85$ & $140 / 90$ & 89 (84 to 92$)$ & 35 (25 to 45$)$ & 1.35 (1.17 to 1.57$)$ & $0.33(0.22$ to 0.50$)$ \\
\hline Zabludowski $1992^{53}$ & 90 (diastolic) & 90 (diastolic) & 81 (71 to 89$)$ & 47 (36 to 57$)$ & $1.53(1.23$ to 1.90$)$ & $0.40(0.24$ to 0.66$)$ \\
\hline
\end{tabular}

${ }^{*}$ Modesti ${ }^{45}$ used 95\% confidence limit of controls (clinic normotension) for day (84 mm Hg) diastolic values. Larkin ${ }^{43}$ used 143/91 (day), $139 / 87$ (24 h), $127 / 79$ (night time). Ozdemir ${ }^{47}$ used ambulatory threshold $140 / 90$ (waking) and $120 / 80$ (sleeping) if \% of raised readings exceeded $20 \%$. 
Table 6 | Sensitivity and specificity for ambulatory monitoring compared with home monitoring of blood pressure

\begin{tabular}{|c|c|c|c|c|c|c|}
\hline \multirow[b]{2}{*}{ Study } & \multicolumn{2}{|c|}{ Diagnostic thresholds $(\mathrm{mm} \mathrm{Hg})$} & \multirow[b]{2}{*}{ Sensitivity \% (95\% Cl) } & \multirow[b]{2}{*}{ Specificity \% (95\% Cl) } & \multicolumn{2}{|c|}{ Likelihood ratio $(95 \% \mathrm{Cl})$} \\
\hline & Ambulatory & Home & & & Positive & Negative \\
\hline Bayo $2006^{34}$ & $135 / 85$ & $135 / 85$ & 76 (66 to 83 ) & 50 (38 to 62$)$ & 1.51 (1.18 to 1.95$)$ & 0.49 (0.32 to 0.73 ) \\
\hline Bayo $2006^{34}$ & $135 / 85$ & $130 / 80$ & 88 (80 to 93 ) & 34 (23 to 46$)$ & 1.33 (1.11 to 1.58$)$ & 0.36 (0.20 to 0.66$)$ \\
\hline Den Hond $2003^{36}$ & $135 / 85$ & $135 / 85$ & 89 (84 to 92 ) & 68 (43 to 87$)$ & 2.81 (1.45 to 5.45$)$ & 0.17 (0.10 to 0.27$)$ \\
\hline Denolle $1995^{37}$ & $139 / 87$ & $127 / 83$ & 91 (59 to 100$)$ & 40 (5 to 85 ) & $1.52(0.72$ to 3.18$)$ & 0.23 (0.03 to 1.96$)$ \\
\hline Larkin $1998^{43}$ & $140 / 90$ & $140 / 90$ & 60 (39 to 79 ) & 92 (79 to 98$)$ & 7.60 (2.45 to 23.58$)$ & $0.43(0.27$ to 0.71$)$ \\
\hline Llibre $2006^{44}$ & $135 / 85$ & $140 / 90$ & 48 (35 to 61$)$ & 77 (68 to 85$)$ & 2.11 (1.34 to 3.33$)$ & 0.68 (0.52 to 0.88$)$ \\
\hline Stergiou $2000^{49}$ & $140 / 90$ & $140 / 90$ & 75 (64 to 84$)$ & 76 (62 to 87$)$ & $3.11(1.87$ to 5.18$)$ & $0.33(0.22$ to 0.50$)$ \\
\hline Stergiou $2000^{49}$ & $135 / 85$ & $135 / 85$ & 90 (83 to 95$)$ & 69 (50 to 84$)$ & 2.88 (1.72 to 4.84$)$ & 0.14 (0.08 to 0.27$)$ \\
\hline
\end{tabular}


Table 7| Pooled result for performance of home and clinic measurement of blood pressure in diagnosis of hypertension

\begin{tabular}{cccccc}
\multicolumn{2}{c}{ Sensitivity } & & \multicolumn{2}{c}{ Specificity } \\
\cline { 2 - 2 }$(95 \% \mathrm{Cl})$ & Relative $(95 \% \mathrm{Cl})$ & & $\%(95 \% \mathrm{Cl})$ & Relative
\end{tabular}

Home measurement ( $n=3) 85.7$ (78.0 to 91.0 ) 1.15 (0.95 to 1.39 ), $P=0.16 \quad 62.4$ (48.0 to 75.0 ) 0.79 (0.40 to 1.55 ), $P=0.49$

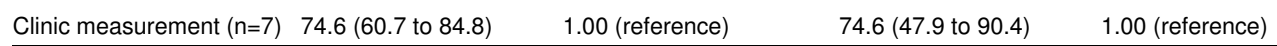


Table 8 | Thresholds for measurement of blood pressure for diagnosis of hypertension in clinic and home measurements

\begin{tabular}{|c|c|c|c|c|}
\hline \multirow[b]{2}{*}{ Test threshold* } & \multicolumn{2}{|c|}{ Sensitivity } & \multicolumn{2}{|c|}{ Specificity } \\
\hline & $\%(95 \% \mathrm{Cl})$ & Relative (95\% Cl) & $\%(95 \% \mathrm{Cl})$ & Relative (95\% Cl) \\
\hline \multicolumn{5}{|c|}{ Clinic blood pressure test } \\
\hline $140 / 90(n=7)$ & 74.7 (61.7 to 84.4$)$ & 1.0 (reference) & 74.8 (49.8 to 89.8$)$ & 1.0 (reference) \\
\hline $150 / 90(n=1)$ & 66.3 (28.3 to 90.8$)$ & 0.89 (0.51 to 1.55$), P=0.68$ & 86.2 (24.8 to 99.2$)$ & 1.15 (0.71 to 1.88$), P=0.57$ \\
\hline \multicolumn{5}{|c|}{ Home blood pressure test } \\
\hline $140 / 90(n=1)$ & 52.6 (34.7 to 69.8 ) & 0.63 (0.45 to 0.88$), P=0.01$ & 80.3 (67.9 to 88.7$)$ & $1.42(1.20$ to 1.68$), P<0.001$ \\
\hline $135 / 85(n=3)$ & 83.2 (76.1 to 88.5 ) & 1.0 (reference) & 56.7 (46.4 to 66.4$)$ & 1.0 (reference) \\
\hline $130 / 80(n=1)$ & 91.8 (84.4 to 95.8$)$ & 1.10 (1.03 to 1.18$), P=0.01$ & 41.4 (30.1 to 53.5$)$ & 0.73 ( 0.57 to 0.93 ), $P=0.01$ \\
\hline
\end{tabular}

${ }^{*} \mathrm{n}=$ number of studies. 
Table 9| Probability (\%) that test diagnosis is correct (judged by reference standard of ambulatory monitoring) given likelihood ratios (both positive and negative) and different pre-test probabilities (that is, estimates of population prevalence)

\begin{tabular}{lccccc}
\multirow{2}{*}{ Prevalence } & \multicolumn{2}{c}{ Positive } & & \multicolumn{2}{c}{ Negative } \\
\cline { 2 - 3 } $10 \%$ & Home & Clinic & & Home & Clinic \\
\hline $30 \%$ & 19 & 25 & & 97 & 96 \\
\hline $50 \%$ & 47 & 56 & & 90 & 87 \\
\hline Sensitivity analysis $50 \%$ & 67 & 61 & & 80 & 76 \\
\hline
\end{tabular}




\section{Figures}

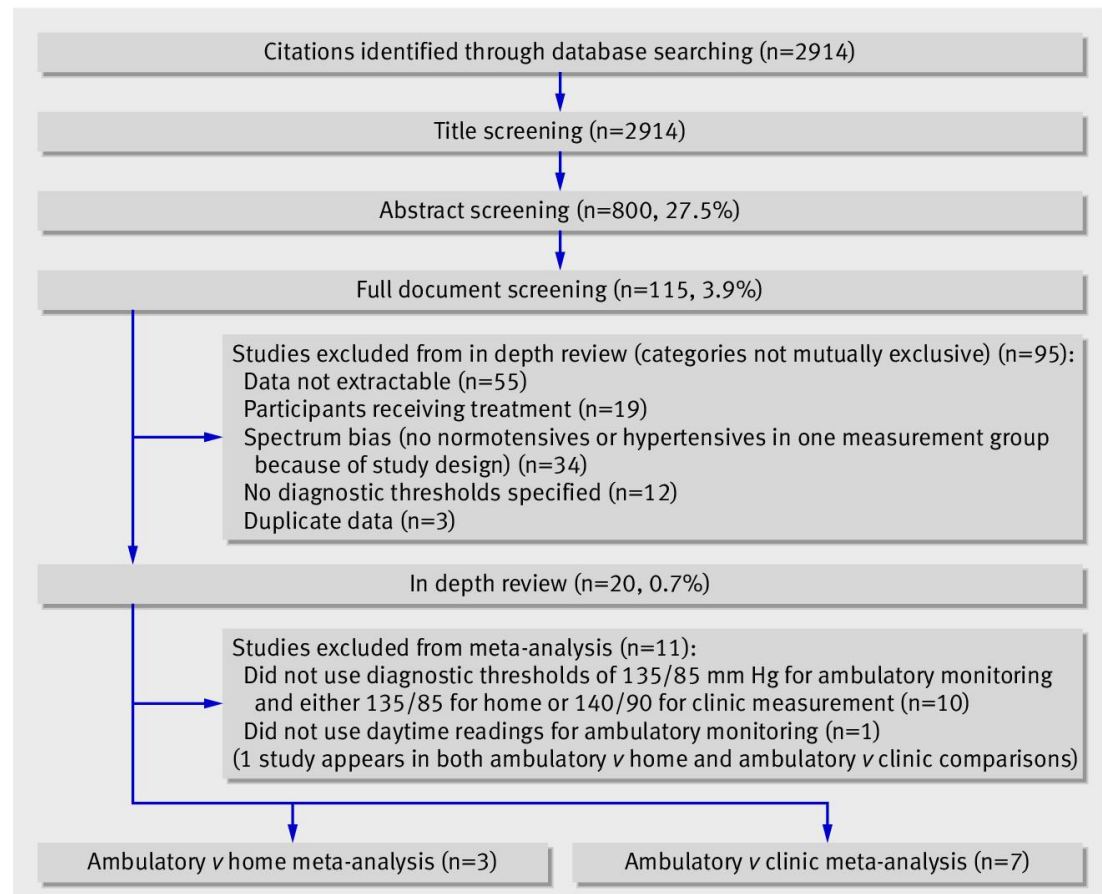

Fig 1 Selection of studies to include in analysis of effectiveness of different types of measuring blood pressure for diagnosis of hypertension

\begin{tabular}{|c|c|c|c|c|c|c|c|c|}
\hline \multirow[b]{2}{*}{ Study } & \multicolumn{2}{|c|}{ Positive } & \multicolumn{2}{|c|}{ Negative } & \multirow[b]{2}{*}{ Sensitivity } & \multirow[b]{2}{*}{ Specificity } & \multirow[b]{2}{*}{ Sensitivity } & \multirow[b]{2}{*}{ Specificity } \\
\hline & True & False & True & False & & & & \\
\hline \multicolumn{9}{|c|}{ Threshold: $135 / 85 \mathrm{~mm} \mathrm{Hg}$ for home monitoring $\mathrm{v} 135 / 85 \mathrm{~mm} \mathrm{Hg}$ for ambulatory monitoring } \\
\hline Bayo $2006^{34}$ & 81 & 37 & 26 & 37 & $76(66$ to 83$)$ & $50(38$ to 62$)$ & $\rightarrow$ & $\longrightarrow-$ \\
\hline Den Hond $2003^{36}$ & 202 & 6 & 26 & 13 & 89 (84 to 92) & $68(43$ to 87$)$ & $\rightarrow$ & $=$ \\
\hline Stergiou $2000^{49}$ & 91 & 10 & 10 & 22 & $90(83$ to 95$)$ & $69(50$ to 84$)$ & $\rightarrow$ & $\longrightarrow$ \\
\hline \multicolumn{9}{|c|}{ Threshold: $140 / 90 \mathrm{~mm} \mathrm{Hg}$ for clinic monitoring $v$} \\
\hline Flores $2000^{39}$ & 7 & 20 & 0 & 20 & $100(59$ to 100$)$ & $50(34$ to 66$)$ & $\longrightarrow$ & $\longrightarrow$ \\
\hline Ogedegbe $2008^{46}$ & 90 & 20 & 43 & 85 & 68 (59 to 76$)$ & 81 (72 to 88$)$ & - & $\rightarrow$ \\
\hline Shimbo $2009^{48}$ & 75 & 9 & 57 & 88 & 57 (48 to 65$)$ & 91 (83 to 96$)$ & $\rightarrow$ & $\rightarrow$ \\
\hline Stergiou $2000^{49}$ & 82 & 12 & 19 & 20 & 81 (72 to 88$)$ & 63 (44 to 79$)$ & $\rightarrow$ & $\longrightarrow$ \\
\hline Stergiou $2005^{50}$ & 195 & 33 & 33 & 27 & 86 (80 to 90$)$ & 45 (32 to 58$)$ & $\Rightarrow$ & $\longrightarrow$ \\
\hline Trudel $2009^{51}$ & 221 & 32 & 356 & 1761 & 38 (34 to 42$)$ & 98 (97 to 99$)$ & - & . \\
\hline Ungar $2004^{52}$ & 254 & 66 & 33 & 35 & 89 (84 to 92$)$ & 35 (25 to 45$)$ & $=$ & $\rightarrow$ \\
\hline
\end{tabular}

Fig 2 Paired forest plots of sensitivity and specificity for home $v$ ambulatory and clinic $v$ ambulatory. Multiple analyses were possible for Bayo et $\mathrm{al}^{34}$ and Stergiou et $\mathrm{al}^{49}$ (see tables 5 and 6) 


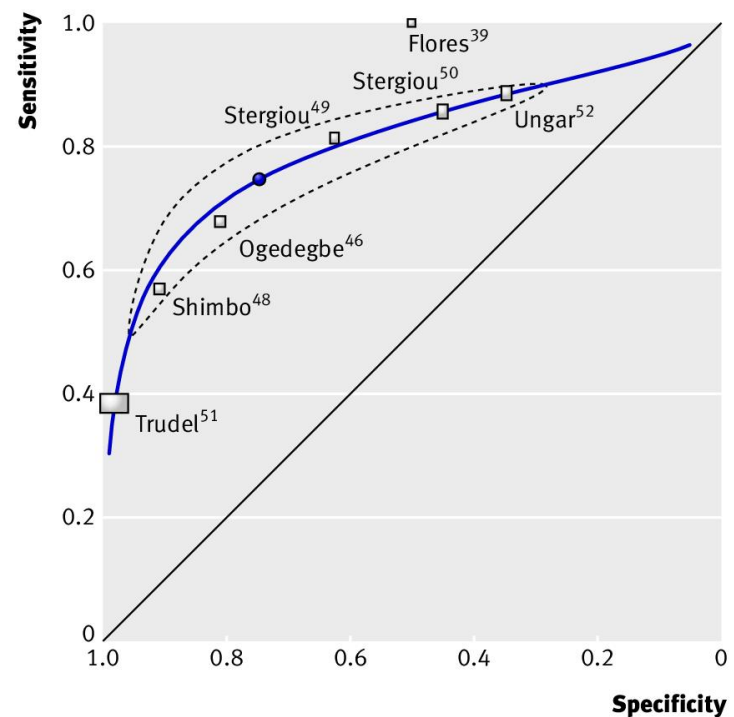

Fig 3 Hierarchical summary receiver operating characteristic plot for clinic $v$ ambulatory measurement of blood pressure for diagnosis of hypertension

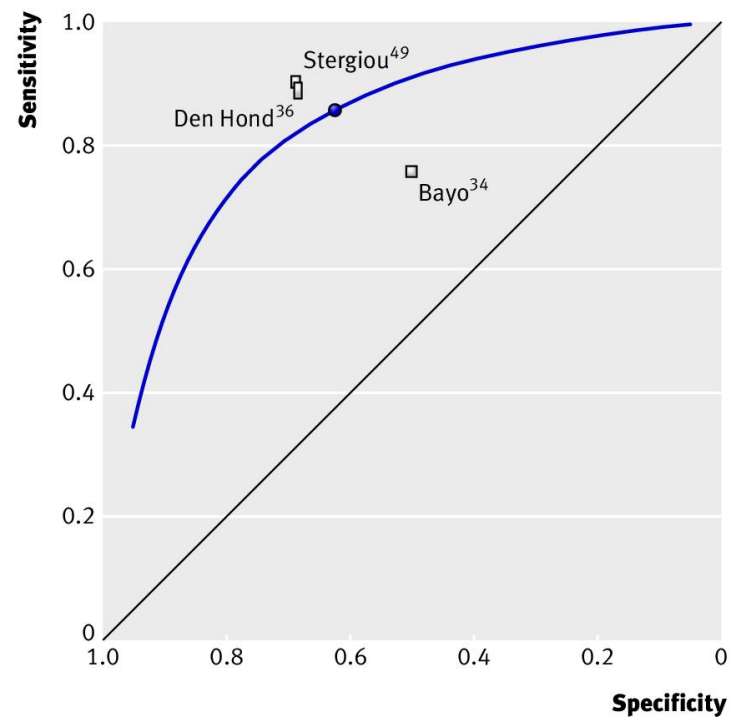

Fig 4 Hierarchical summary receiver operating characteristic plot for home $v$ ambulatory measurement of blood pressure for diagnosis of hypertension 